\title{
Perceptions of Immediate Written Feedback Provided to SLP Graduate Clinicians During Tele-Therapy Sessions
}

\author{
Darya Hinman \\ Kean University, dhinman@kean.edu \\ Sarah Patten \\ Kean University, spatten@kean.edu \\ Mahchid Namazi \\ Kean University, mnamazi@kean.edu \\ DOI: https://doi.org/10.30707/TLCSD5.2.1624983591.646431
}

Follow this and additional works at: https://ir.library.illinoisstate.edu/tlcsd

Part of the Speech Pathology and Audiology Commons

\section{Recommended Citation \\ Hinman, Darya; Patten, Sarah; and Namazi, Mahchid (2021) "Perceptions of Immediate Written Feedback Provided to SLP Graduate Clinicians During Tele-Therapy Sessions," Teaching and Learning in Communication Sciences \& Disorders: Vol. 5: Iss. 2, Article 1. DOI: https://doi.org/10.30707/TLCSD5.2.1624983591.646431 \\ Available at: https://ir.library.illinoisstate.edu/tlcsd/vol5/iss2/1}

This Scholarship of Teaching and Learning Research is brought to you for free and open access by ISU ReD: Research and eData. It has been accepted for inclusion in Teaching and Learning in Communication Sciences \& Disorders by an authorized editor of ISU ReD: Research and eData. For more information, please contact ISUReD@ilstu.edu. 


\title{
Perceptions of Immediate Written Feedback Provided to SLP Graduate Clinicians During Tele-Therapy Sessions
}

\author{
Abstract \\ Given the status of clinical practice and the heavy reliance on technology due to COVID-19, it is important \\ to investigate clinical supervision practices. The purpose of this study was to determine whether \\ immediate feedback using technology was beneficial for a university clinical setting specifically where \\ current supervision of students is undertaken via a virtual platform. The chat function via the Zoom \\ teletherapy platform was used to deliver immediate written feedback to SLP graduate clinicians. Utilizing \\ technology allowed supervisors to provide immediate, in-session written feedback to SLP graduate \\ clinicians. The objective was to investigate the perceptions of immediate feedback for the SLP graduate \\ clinicians and their supervisors. The objective was met through the utilization of surveys at the end of the \\ study which indicated a preference for immediate feedback for both the supervisors and the SLP \\ graduate clinicians. Having the ability to use technology helped supervisors support the SLP graduate \\ clinicians discretely, especially given the nature of remote supervision. Immediate written feedback \\ utilizing technology should be considered as a means of supporting the SLP graduate clinicians in \\ developing their clinical skills.
}

\section{Keywords}

remote supervision, tele-supervision, teletherapy, SLP graduate clinician feedback

\section{Cover Page Footnote}

Darya Hinman would like to acknowledge Dr. Mahchid Namazi and Dr. Sarah Patten for their mentorship throughout the SLPD program at Kean University. Darya would also like to thank Kean University, her friends and family, as well as her colleagues for the support! 
During a clinical practicum, it is crucial for the speech-language pathology (SLP) graduate clinician to gain knowledge, independence, as well as experience to promote the development of skills necessary to become a competent clinician. A clinical supervisor serves as a mentor and educator within a clinical placement; therefore, the feedback the clinical supervisor provides to the SLP graduate clinician is pivotal. While enrolled in a graduate school SLP program, a graduate clinician is assigned to complete several clinical practica either at the university's onsite clinic or at a specified off-site clinical placement. A supervisor is assigned to the SLP graduate clinician during each clinical practicum experience. A supervisor's role is to mentor the new clinician in developing clinical skills and bridging the gap between theory and practice. Onsite clinics typically have the facility to record the SLP graduate clinician/client session, supporting opportunities for feedback and discussion after the event has taken place.

In previous years, the American Speech-Language-Hearing Association (ASHA) mandated for supervisors of SLP graduate clinicians to hold their certificate of clinical competence from ASHA, without any other qualification or training in supervision. In 2020, ASHA's standards of practice have additional supervision training obligations (ASHA, 2018). Before overseeing students, ASHA now requires at least two hours of professional development or continuing education in supervision. While it is an appropriate requirement and facilitates a better preparation for clinical supervision, other modifications should be considered. This requirement must be completed only once and is not expected to be completed every licensing period. There is also limited literature available on supervision through teletherapy, although many SLPs have changed their services to be remote due to COVID-19 restrictions. As more research is conducted in the areas of supervision, setting specific guidelines and expectations for supervisors should be implemented. Guidelines providing suggested goals, interactions, and perhaps feedback methods that are supported by evidence-based practice may influence the preparation of clinical supervisors and improve the learning experience of the graduate clinicians.

\section{Literature Review}

\section{Knowles and Adult Learning Theory}

As SLP graduate clinicians begin their training in graduate schools, the suitable learning approach changes from pedagogy to andragogy as SLP graduate clinicians transition into adult learners. Knowles (1975) argued that the emphasis of adult education is to create lifelong learners. The idea behind lifelong learners is that it takes into consideration "physical, mental, emotional, social, spiritual, and occupational development through the life span" (Knowles, 1975, p. 87). Knowles (1980) proposed six assumptions to adult learning. The six assumptions to learning proposed by Knowles (1980) are that adults are self-directed learners, have previous experience, are ready to learn, are problem-oriented versus subject-centered, have internal motivation, and need a reason for learning something. It is claimed that learning is strongly influenced by internal motivation, readiness to learn, and experience. Knowles (1980) argued that our experiences consistently promote new learning. Clinical supervisors must be aware of adult learning theories as they support SLP graduate clinicians in externship placements and throughout the supervisory relationship. Many supervisory models exist; Anderson's model of supervision, however, will be explored in this article as it has been widely used in communication sciences and disorders research. 


\section{Anderson's Model of Supervision}

Studying areas of supervision, specifically in the field of SLP, one will come across Anderson's Model of Supervision (McCrea \& Brasseur, 2019; Anderson, 1988). Anderson's Model of Supervision explores three stages where the SLP graduate clinician is exposed to different styles of interaction. Within the evaluation-feedback stage, the interaction between the SLP graduate clinician and the supervisor is direct and active, where the supervisor plays a leading role. The relationship here involves the supervisor making all clinical decisions. During the transitional stage, the SLP graduate clinician and the supervisor embrace the collaborative stage of the supervisory relationship, where the supervisor allows the SLP graduate clinician to make clinical decisions collaboratively. The goal for this stage is to move towards the SLP graduate clinician's independence so they can reach the self-supervision stage and have a peer-to-peer relationship with the supervisor (McCrea \& Brasseur, 2019; Anderson, 1988).

Within the evaluation-feedback stage, the interaction between the SLP graduate clinician and the supervisor is very direct and active, where the supervisor is a leader. In this stage, the supervisor uses previous experience to suggest treatment approaches and strategies. This stage introduces the concept of exposing adult learners to the rationale for learning. For the SLP graduate clinician's client to be making progress and meeting the established goals, a valid treatment approach should be utilized. During this period, the feedback that the SLP graduate clinician receives is critical. The feedback should be continuously available. As argued by Gordon-Pershey and Walden (2013), such feedback helps the SLP graduate clinician to generalize the concepts and use them with other clients. This stage coincides with Knowles's (1980) assumptions of adult learning. Understanding fundamental approaches with specific clients can help the SLP graduate clinician move towards the next stage in the supervisory model. Such feedback is not readily available to clinicians upon completion of graduate studies; therefore, establishing strong foundational skills is imperative.

These skills then impact the SLP graduate clinician in making a transition to the self-supervision stage as the reliance on feedback provided by the supervisor decreases. The adult learners become independent, self-directed, and have the internal motivation needed to pursue further knowledge as proposed by Goldman (2011). The self-supervision stage is critical. Zorga (1997) argued that if the supervision that occurs during a clinical placement is successful in promoting an individual to have self-supervision skills, it will lead the individual to require less supervision in their workforce because the critical skills required are developed.

In summary, there are several components of adult learning theories that SLP graduate schools should consider in their programs. As discussed previously, providing support through feedback methods early can result in promoting a novice clinician to develop the necessary problem-solving skills necessary for the SLP field. The goal of a graduate school program is to develop clinicians who are not only independent, but can think critically, problem-solve, and be self-directed learners. Because an SLP career requires continuing education courses, clinicians need to become lifelong learners who are driven by their experiences and motivation to learn. It can be argued that these skills are developed throughout experiences and SLPs furthering themselves in their careers; however, the notion of lifelong learning can be promoted within the supervisory relationship one experiences. 


\section{Supervisory Relationship}

The relationship between supervisor and SLP graduate clinician is essential in fostering the growth of the adult learner. The SLP graduate clinician and the supervisor may value different components of a supervisory relationship that contribute to a positive clinical experience. Before beginning a supervisory relationship, a few factors and key components need to be considered. Generational differences, expectations, and adult learning styles are some of the key factors. A discussion regarding adult learning styles is important at the beginning of a supervisory relationship, as different expectations may exist between the supervisor and the SLP graduate clinicians. As discussed by Blevins (2014), millennials, also known as generation Y, expect learning to not only be fun and creative but also to include immediate feedback. Various supervisory feedback methods are currently used by SLP supervisors, but several studies have shown that immediate feedback is the one component the SLP graduate clinicians felt most strongly about, specifically for the current generation of students (Lorio et al., 2016; Ho \& Whitehill, 2009; Taylor et al., 2012; Gurley, 2000). Given COVID-19, many SLP graduate clinicians have been providing services through teletherapy, while expecting to receive support and feedback from their clinical supervisors. Unfortunately, minimal research is available in the areas of remote supervision and technology.

\section{Technology and Supervision}

According to Blevins (2014), Generation Y are experienced technology users. Utilizing technology throughout their childhood, they demonstrate considerable comfort using it in everyday life; however, there is limited literature available. More research is needed that investigates the use of technology to support immediate feedback during supervision, specifically for teletherapy. Using written feedback, such as the chat function, provides an opportunity for the SLP graduate clinicians to receive immediate written feedback discretely without an interruption to the therapy session. This idea of feedback relates to the adult learning theories as this methodology allows SLP graduate clinicians to recognize their limitations in experiences and provides them with a need for learning as well as readiness to learn.

\section{Purpose}

The purpose of this study was to investigate the perceptions of immediate written feedback for the SLP graduate clinicians as well as for their supervisors. This objective was met using surveys at the end of the study which indicated a preference for immediate written feedback for both the supervisors and the SLP graduate clinicians. This study was undertaken to add to the information SLP supervisors may need to improve clinical practica experiences and learning.

\section{Methodology}

The Kean University Institutional Review Board approved this study. This study was conducted at Kean University Center for Communication Disorders (KUCCD), the teaching clinic, via teletherapy and tele-supervision. KUCCD provided SLP services through a HIPAA compliant Zoom teletherapy platform. This methodology allowed the SLP supervisors and the SLP graduate clinicians to engage in written feedback. The Zoom platform features include a private chat function where the immediate written feedback was provided discretely. The information provided 
by this study allows KUCCD to create procedures as well as guidelines for future supervisors and to make recommendations regarding the provision of immediate feedback. A qualitative research design was utilized for this research study conducted at Kean University.

\section{Recruitment and Participants}

Five subjects were recruited via a flyer that was sent through email by the clinic director. The supervisors and SLP graduate clinicians who choose to participate were e-mailed by the principal investigator using their email accounts. Three participants were SLP graduate clinicians who were seeing clients at KUCCD during the summer 2020 semester and their corresponding supervisors. One of the supervisors was overseeing two of the SLP graduate clinicians, while the second supervisor was managing only one SLP graduate clinician. There were 3 dyads, with each dyad providing therapy to 2-3 clients. The principal investigator did not have any access to clients or their data. There was no relationship between the principal investigator and the participants. This researcher was a student in the Kean University's Speech-Language Pathology Doctorate (SLPD) program.

\section{Procedure}

It should be noted that the typical in-person therapy procedure at KUCCD is as follows. SLP graduate clinicians are assigned an SLP supervisor for the semester. SLP graduate clinicians are also assigned 2-3 clients to whom they are providing therapy twice a week. During the session with the client, SLP graduate clinicians are supervised via a live feed using cameras by their SLP supervisor who is in a different room. The client's parents provide KUCCD with their consent for the sessions to be recorded. At any point in time, SLP supervisors can enter the room as needed to provide feedback, suggestions, or strategies. If needed, the SLP supervisor and SLP graduate clinician meet following the session where written and/or verbal feedback is provided.

Due to COVID-19 restrictions, KUCCD offered services to clients via teletherapy. SLP graduate clinicians began delivering teletherapy services to their clients in summer 2020. Their supervisors provided supervision remotely. The principal investigator explored whether the modality of having immediate feedback delivered via written feedback was beneficial to the SLP graduate clinician and the supervisor. This study took 4 weeks to complete. There were 4-6 sessions with the feedback method, which took 3 weeks, and then 1 week was provided for the SLP supervisors and SLP graduate clinicians to complete surveys about their experience. The survey took less than 10 minutes to complete. The two surveys were submitted through Qualtrics (Qualtrics, Provo, UT). One of the surveys for the SLP graduate clinician feedback, and another for the supervisor feedback. This survey included a Likert-type scale as well as open-ended questions. It was piloted by SLPD colleagues to ensure that it was valid to serve for intended purposes. The surveys can be found in Appendices A and B, respectively. The principal investigator analyzed the qualitative data provided from the surveys.

\section{Results}

The results of the surveys were collected using Qualtrics (Qualtrics, Provo, UT). Likert-type scale, as well as open-ended question responses, were analyzed for trends. Due to the small sample size, a thematic analysis was not performed. In addition, the researcher did not present Likert scale 
responses in numerical form. The responses have been presented in accordance with the category names.

\section{Immediate Feedback using the Zoom Platform}

For this portion of the study, there were two supervisor participants and three SLP graduate clinicians. The supervisors overall agreed that the Zoom chat function allowed for teachable moments to occur discretely, without changing the dynamic of the session. Interestingly, the SLP supervisors disagreed regarding their views of the distractibility of their presence on the SLP graduate clinicians, which perhaps could be a result of their perception of themselves. Overall, the supervisors reported that using the technology was easy and effective. Results are listed in Table 1 and Table 2.

Table 1.

\begin{tabular}{|l|l|l|}
\hline $\begin{array}{l}\text { Questions for Supervisors in Support of Immediate Written } \\
\text { Feedback }\end{array}$ & $\begin{array}{l}\text { Participant } \\
\text { 1 Response }\end{array}$ & $\begin{array}{l}\text { Participant } \\
\text { 2 Response }\end{array}$ \\
\hline $\begin{array}{l}\text { I would prefer to provide feedback to the SLP graduate clinician } \\
\text { without interrupting the session }\end{array}$ & Disagree & $\begin{array}{l}\text { Somewhat } \\
\text { Disagree }\end{array}$ \\
\hline $\begin{array}{l}\text { The written feedback (chat function) in Zoom allowed for teachable } \\
\text { moments to occur within the session without changing the dynamic } \\
\text { between the SLP graduate clinician and their client }\end{array}$ & Agree & Agree \\
\hline $\begin{array}{l}\text { When the written feedback (chat function) in Zoom was not used, } \\
\text { there were times I wanted to communicate to the SLP graduate } \\
\text { clinician, but I was unable to }\end{array}$ & Disagree & Agree \\
\hline $\begin{array}{l}\text { I believe my presence within a session is a distraction to the SLP } \\
\text { graduate clinician }\end{array}$ & Disagree & Agree \\
\hline $\begin{array}{l}\text { I believe my presence within a session is a distraction to the client } \\
\text { Domewhat } \\
\text { Disagree }\end{array}$ & $\begin{array}{l}\text { Somewhat } \\
\text { Disagree }\end{array}$ \\
\hline
\end{tabular}

Table 2.

\begin{tabular}{|l|l|l|}
\hline Questions for Supervisors Against Immediate Written Feedback & $\begin{array}{l}\text { Participant 1 } \\
\text { Response }\end{array}$ & $\begin{array}{l}\text { Participant } 2 \\
\text { Response }\end{array}$ \\
\hline Technology is difficult for me to use & Disagree & Disagree \\
\hline $\begin{array}{l}\text { It was difficult to provide feedback through the written feedback } \\
\text { (chat function) in Zoom }\end{array}$ & $\begin{array}{l}\text { Strongly } \\
\text { Disagree }\end{array}$ & $\begin{array}{l}\text { Strongly } \\
\text { Disagree }\end{array}$ \\
\hline $\begin{array}{l}\text { I would have preferred to have entered the therapy room to } \\
\text { provide feedback instead of typing the written feedback }\end{array}$ & Disagree & Disagree \\
\hline $\begin{array}{l}\text { The written feedback (chat function) in Zoom was a distraction to } \\
\text { the SLP graduate clinician during the sessions }\end{array}$ & Disagree & $\begin{array}{l}\text { Somewhat } \\
\text { Disagree }\end{array}$ \\
\hline $\begin{array}{l}\text { The written feedback (chat function) in Zoom was a distraction to } \\
\text { the client during the session }\end{array}$ & $\begin{array}{l}\text { Strongly } \\
\text { Disagree }\end{array}$ & $\begin{array}{l}\text { Strongly } \\
\text { Disagree }\end{array}$ \\
\hline
\end{tabular}

The SLP graduate clinicians reported utilization of immediate written feedback as being beneficial in the content provided. They all agreed that the Zoom chat function was easy to use, and minimally distracting. One of the three participants reported the timing of the feedback provided was insignificant to them, where two participants supported this component. The SLP graduate 
clinicians all agreed that they would prefer to have access to this method in the future as it was discrete and helpful. The responses to the questions are provided in Table 3 and Table 4.

Table 3.

\begin{tabular}{|l|l|l|l|}
\hline $\begin{array}{l}\text { Questions for SLP Graduate Clinician in Support } \\
\text { of Immediate Written Feedback }\end{array}$ & $\begin{array}{l}\text { Participant } \\
\text { 1 Response }\end{array}$ & $\begin{array}{l}\text { Participant } \\
\text { 2 Response }\end{array}$ & $\begin{array}{l}\text { Participant } \\
\text { 3 Response }\end{array}$ \\
\hline $\begin{array}{l}\text { It was beneficial to receive immediate feedback } \\
\text { from my supervisor via written feedback (chat } \\
\text { function) in Zoom }\end{array}$ & $\begin{array}{l}\text { Agree } \\
\text { Agree }\end{array}$ & $\begin{array}{l}\text { Strongly } \\
\text { Agree }\end{array}$ \\
\hline $\begin{array}{l}\text { The content of the feedback was helpful during the } \\
\text { session }\end{array}$ & Agree & $\begin{array}{l}\text { Strongly } \\
\text { Agree }\end{array}$ & $\begin{array}{l}\text { Strongly } \\
\text { Agree }\end{array}$ \\
\hline $\begin{array}{l}\text { I want immediate feedback available for all my } \\
\text { sessions with my clients }\end{array}$ & Agree & $\begin{array}{l}\text { Strongly } \\
\text { Agree }\end{array}$ & Agree \\
\hline
\end{tabular}

Table 4.

\begin{tabular}{|l|l|l|l|}
\hline $\begin{array}{l}\text { Questions for SLP Graduate Clinician Against } \\
\text { Immediate Written Feedback }\end{array}$ & $\begin{array}{l}\text { Participant } \\
\text { 1 Response }\end{array}$ & $\begin{array}{l}\text { Participant } \\
\text { 2 Response }\end{array}$ & $\begin{array}{l}\text { Participant } \\
\text { 3 Response }\end{array}$ \\
\hline $\begin{array}{l}\text { I would have preferred for the supervisor to have } \\
\text { entered the room during my session }\end{array}$ & Disagree & $\begin{array}{l}\text { Strongly } \\
\text { Disagree }\end{array}$ & Disagree \\
\hline $\begin{array}{l}\text { The written feedback (chat function) in Zoom was } \\
\text { distracting to me during the session }\end{array}$ & Disagree & Disagree & Disagree \\
\hline $\begin{array}{l}\text { The written feedback (chat function) in Zoom } \\
\text { distracted my client during the session }\end{array}$ & Disagree & $\begin{array}{l}\text { Somewhat } \\
\text { Agree }\end{array}$ & $\begin{array}{l}\text { Somewhat } \\
\text { Disagree }\end{array}$ \\
\hline $\begin{array}{l}\text { The written feedback (chat function) in Zoom was } \\
\text { difficult to use as I had to type back my questions to } \\
\text { the supervisor }\end{array}$ & Disagree & Disagree & Disagree \\
\hline $\begin{array}{l}\text { The written feedback (chat function) in Zoom was } \\
\text { difficult to use as it took time for me to ask for } \\
\text { clarification from the supervisor }\end{array}$ & Disagree & $\begin{array}{l}\text { Strongly } \\
\text { Disagree }\end{array}$ & Disagree \\
\hline The timing of feedback was insignificant to me & Disagree & $\begin{array}{l}\text { Somewhat } \\
\text { Disagree }\end{array}$ & $\begin{array}{l}\text { Somewhat } \\
\text { Agree }\end{array}$ \\
\hline
\end{tabular}

\section{Open-ended Questions}

Four open-ended questions were asked regarding the use of immediate written feedback. The questions focused on the frequency of feedback, the content of feedback, benefits of using immediate feedback, as well as additional comments and information/suggestions. SLP graduate clinicians reported that they liked immediate feedback as they were able to implement changes immediately. The open-ended responses included the following:

It helped me move through my sessions smoothly and if something wasn't working I had other options suggested to me. (SLP graduate clinician)

Personally, I had one specific client that I struggled with especially because it was through teletherapy and we were not able to establish in-person rapport. Having my supervisor provide immediate feedback/advice when conducting therapy was very helpful. She provided direct 
input on what to say/to do or guidance around how to do a certain technique that was very valuable. (SLP graduate clinician)

I benefitted from knowing and being able to change the way I was doing the activity and realize in the moment what was the best way to do it. (SLP graduate clinician)

Regarding the content and frequency of the feedback, SLP graduate clinicians and the supervisors reported that relevant and "in the moment" content was most suitable. Such feedback was provided 3-4 times within a session:

I tried to use it sparingly, so as not to distract the clinician. However, when the clinician or client seemed frustrated I always made a suggestion. Other times, I would use the chat to point out opportunities for additional prompting of trials. (Supervisor)

Finally, the SLP graduate clinicians and their supervisors reported that using feedback in this manner was valuable. They reported the following:

Overall, I would say that immediate feedback was helpful for my personally. Part of the challenge is being able to multi-task (e.g., read the chat while also facilitating the session). However, I found that if you are clear with the supervisor that you are not able to respond right away then this should clear any misunderstanding. (SLP graduate clinician)

I found the feedback very beneficial, the more I used it the more comfortable I felt. (SLP graduate clinician)

Quick and easy for student to adjust in the moment; non distracting to clients. (Supervisor)

In conclusion, it appeared that both SLP graduate clinicians and supervisors preferred the use of technology to provide immediate feedback discretely. Although there were areas of weakness, such as technological issues, this was an appropriate introduction into various feedback methods to support students during their SLP clinical rotations to increase confidence as well as morale.

\section{Discussion}

As discussed previously, part of ASHA's new requirement is to have a clinical supervisor complete continuing education courses in supervision (ASHA, 2018). An SLP graduate clinician is guided by a clinical supervisor during the externship experience to develop essential skills in the field of speech-language pathology. The feedback the SLP graduate clinician receives during the supervisory experience is critical. An SLP graduate program's goals are to produce clinicians that have the internal motivation and are ready to learn, which are qualities that align with Knowles's (1980) adult learning theory. As reviewed in the introduction, Anderson's Model of Supervision is a continuum on which the SLP graduate clinicians experience three stages which are the evaluation-feedback stage, then the transitional stage, and then the self-supervision stage (McCrea $\&$ Brasseur, 2019). The evaluation-feedback stage lays a crucial foundation for the supervisory experience, as it includes opportunities for feedback to be provided to the SLP graduate clinicians by their supervisors. 
The traditional feedback that the SLP graduate clinicians at KUCCD received usually occurred after the fact. As discussed in the methods section, the SLP graduate clinicians were synchronously observed by their supervisors located in an adjacent faculty room. If the supervisors needed to intervene with their physical presence, they could do so at the expense of changing the dynamic of the session. Supervisors had to be cognizant that if the situation occurred where they had to intervene during a session with a client, it was not confidential as others were present. In summer 2020 KUCCD began providing teletherapy services for the first time due to COVID-19. Previously, such practices were not performed. This study was undertaken to explore the use of technology for remote supervision during teletherapy to allow supervisors to provide effective feedback discreetly.

As explained in the methods section, a survey was undertaken by the SLP graduate clinicians as well as their supervisors following their experiences using the Zoom chat option as a means of providing immediate written feedback during clinical sessions. This modality was investigated as Generation Y has a lifetime of experience using technology (Blevins, 2014). The surveys took place following the delivery of immediate written feedback under student provision of services to clients via teletherapy.

The results indicated that for the supervisors the chat option in the Zoom platform allowed for teachable moments to occur without an interruption to the session. It presented opportunities for positive reinforcement as well as suggestions in therapeutic approaches. Interestingly, there was a divide between the supervisors' perceptions of themselves as distractors to the SLP graduate students and their clients. One of the supervisors felt her presence was a distraction, while the other supervisor did not. The SLP graduate clinicians all reported that using the chat function was not a distraction to them within the session; however, one reported the need for clarification from a supervisor was challenging via chat. The immediate feedback as stated by Gordon-Pershey and Walden (2013) assisted the SLP graduate clinician in generalizing the concepts and applying them to future clients. Again, findings correspond with Knowles (1980) and his assumptions about adult learning. Applying foundational skills and approaches can assist with moving the SLP graduate clinician towards the self-supervision stage in Anderson's Model of Supervision (McCrea \& Brasseur, 2019; Anderson, 1988).

The supervisors all reported that entering the room would not have been preferred as technology allowed them to provide feedback discretely. In the future, supervisor's perspectives should be investigated further as the current literature review focused on SLP graduate clinician's perspectives. Additionally, the SLP graduate clinicians reported that the clients were not distracted by the immediate feedback they had received, and it allowed them to receive direct input regarding the outcomes of their approach. The immediate feedback received was influenced by the type of client, but typically they received feedback 3-5 times within the session.

\section{Limitations of the Study}

The limitations to this current study included the small sample size. Expanding the study to other universities could aid in collecting further data and investigating the benefits of using immediate feedback in teletherapy settings. As mentioned in the discussion section, the literature review 
primarily focused on SLP graduate clinicians' perspectives of immediate written feedback methods. The content and frequency of the feedback were not controlled by the researcher. This would be an area worthy of investigation in the future.

\section{Conclusion}

Previous literature demonstrated that the SLP graduate clinicians found immediate feedback beneficial in increasing self-confidence (Means \& McCaffrey, 2019). The current study supports the use of immediate feedback via technology using the surveys discussed. As noted in the survey results, the SLP graduate clinicians prefer to have immediate feedback available to them for all future sessions with the utilization of technology. The goal of SLP graduate externships is to prepare future clinicians for the SLP field. Immediate feedback is an important component of such an experience and therefore should be provided effectively by the supervisors.

\section{Disclosures}

The authors of the article are employed by Kean University.

The first author attended Kean University, where she completed the SLPD program.

\section{References}

American Speech-Language-Hearing Association (2018). Upcoming changes to the ASHA certification standards for 2020 overview \& concepts. https://www.asha.org/news/2018/upcoming-changes-to-the-asha-certification-standards-for2020-overview-and-background/

Anderson, J. L. (1988) The supervisory process in speech language pathology and audiology. Pro-Ed.

Blevins, S. (2014). Nurses as educators: Understanding learning styles. MEDSURG Nursing, 23(1), 59-60.

Goldman, S. (2011). Enhancing adult learning in clinical supervision. Academic Psychiatry, 35(5), 302-306. https://doi.org/10.1176/appi.ap.35.5.30

Gordon-Pershey, M., \& Walden Patrick, R. (2013). Supervisor and supervisee perceptions of an adult learning model of graduate student supervision. Perspectives on Administration and Supervision, 23(1), 12-21. https://doi.org/10.1044/aas23.1.12

Gurley, J. M. (2000). Supervisory feedback in speech-language pathology: Preferences and practices [Master's thesis, East Tennessee State University]. East Tennessee State University Digital Archive https://dc.etsu.edu/cgi/viewcontent.cgi? article=1040\&context=etd

Ho, D. W. L., \& Whitehill, T. (2009). Clinical supervision of speech-language pathology students: Comparison of two models of feedback. International Journal of Speech-Language Pathology, 11(3), 244-255. 
Knowles, M. S. (1980). The modern practice of adult education: From pedagogy to andragogy. (2nd ed.). Cambridge Books.

Knowles, M. (1980). Malcolm Knowles on. Training \& Development Journal, 34(5), 96.

Knowles, M. S. (1975). Adult education: New dimensions. Educational Leadership, 33(2), 85.

Lorio Ciera, M., Delehanty Abigail, D., \& Woods Juliann, J. (2016). Digital platforms and supervisory feedback to graduate SLP graduate clinicians. Perspectives of the ASHA Special Interest Groups, 1(11), 18-34. https://doi.org/10.1044/persp1.SIG11.18

McCrea, E. S., \& Brasseur, J. A. (2019). The clinical education and supervisory process in speech-language pathology and audiology ( $1^{\text {st }}$ Edition). SLACK Incorporated.

Means, J. W., \& McCaffrey, C. (2019). Enhancing clinical supervision using high-definition real-time recording, annotation, and Bluetooth technology. Perspectives of the ASHA Special Interest Groups, 4(2), 356-362. https://doi.org/10.1044/2019_PERS-SIG11-2018-0020

Qualtrics (Version, March 2021). Provo, UT. https://www.qualtrics.com

Taylor, K., White, E., Kaplan, R., \& O’Rourke Colleen, M. (2012). University: The supervisory process in speech-language pathology: graduate students' perspective. Perspectives on Administration and Supervision, 22(2), 47-54. https://doi.org/10.1044/aas22.2.47

Zorga, S. (1997). Supervision process seen as a process of experiential learning. The Clinical Supervisor, 16(1), 145-161. https://doi.org/10.1300/J001v16n01_08 


\section{Appendix A}

\section{Survey for supervisors:}

1. Please make the appropriate selection about your age range (18-30, 30-40, 40-50, 50+)

2. Please make the appropriate selection: I have been a supervisor for (Less than 1 year, 1-5 years, 5+ years)

3. Technology is difficult for me to use (Strongly Agree, Agree, Somewhat Agree, Disagree, Somewhat Disagree, Strongly Disagree)

4. I would prefer to provide feedback to the SLP graduate clinician without interrupting the session (Strongly Agree, Agree, Somewhat Agree, Disagree, Somewhat Disagree, Strongly Disagree)

5. It was difficult to provide feedback through the written feedback (chat function) in Zoom (Strongly Agree, Agree, Somewhat Agree, Disagree, Somewhat Disagree, Strongly Disagree)

6. I would have preferred to have entered the therapy room to provide feedback instead of typing the written feedback (Strongly Agree, Agree, Somewhat Agree, Disagree, Somewhat Disagree, Strongly Disagree)

7. The written feedback (chat function) in Zoom was a distraction to the SLP graduate clinician during the sessions (Strongly Agree, Agree, Somewhat Agree, Disagree, Somewhat Disagree, Strongly Disagree)

8. The written feedback (chat function) in Zoom was a distraction to the client during the session (Strongly Agree, Agree, Somewhat Agree, Disagree, Somewhat Disagree, Strongly Disagree)

9. The written feedback (chat function) in Zoom allowed for teachable moments to occur within the session without changing the dynamic between the SLP graduate clinician and their client (Strongly Agree, Agree, Somewhat Agree, Disagree, Somewhat Disagree, Strongly Disagree)

10. When the written feedback (chat function) in Zoom was not used, there were times I wanted to communicate to the SLP graduate clinician, but I was unable to (Strongly Agree, Agree, Somewhat Agree, Disagree, Somewhat Disagree, Strongly Disagree)

11. I believe my presence within a session is a distraction to the SLP graduate clinician (Strongly Agree, Agree, Somewhat Agree, Disagree, Somewhat Disagree, Strongly Disagree)

12. I believe my presence within a session is a distraction to the client (Strongly Agree, Agree, Somewhat Agree, Disagree, Somewhat Disagree, Strongly Disagree)

13. Open-ended--When did you provide feedback to the SLP graduate clinician and how did you make that judgement call?

14. Open-ended-- What did you like about the written feedback (chat function) in Zoom?

15. Open-ended-- How could we improve the written feedback (chat function) in Zoom or use it differently?

16. Open-ended-- Any additional comments or suggestions? 


\section{Appendix B}

\section{Survey for SLP Graduate Clinicians:}

1. Please pick the answer that describes your age range (18-22, 23-26, 26+)

2. Please pick the answer that describes your current status ( First year graduate student, Second year graduate student)

3. It was beneficial to receive immediate feedback from my supervisor via written feedback (chat function) in Zoom (Strongly Agree, Agree, Somewhat Agree, Disagree, Somewhat Disagree, Strongly Disagree)

4. I would have preferred for the supervisor to have entered the room during my session (Strongly Agree, Agree, Somewhat Agree, Disagree, Somewhat Disagree, Strongly Disagree)

5. The written feedback (chat function) in Zoom was distracting to me during the session (Strongly Agree, Agree, Somewhat Agree, Disagree, Somewhat Disagree, Strongly Disagree)

6. The written feedback (chat function) in Zoom distracted my client during the session (Strongly Agree, Agree, Somewhat Agree, Disagree, Somewhat Disagree, Strongly Disagree)

7. The written feedback (chat function) in Zoom was difficult to use as I had to type back my questions to the supervisor (Strongly Agree, Agree, Somewhat Agree, Disagree, Somewhat Disagree, Strongly Disagree)

8. The written feedback (chat function) in Zoom was difficult to use as it took time for me to ask for clarification from the supervisor (Strongly Agree, Agree, Somewhat Agree, Disagree, Somewhat Disagree, Strongly Disagree)

9. The feedback I received from my supervisor was client dependent (Strongly Agree, Agree, Somewhat Agree, Disagree, Somewhat Disagree, Strongly Disagree)

10. The content of the feedback was helpful during the session (Strongly Agree, Agree, Somewhat Agree, Disagree, Somewhat Disagree, Strongly Disagree)

11. The timing of feedback was insignificant to me (Strongly Agree, Agree, Somewhat Agree, Disagree, Somewhat Disagree, Strongly Disagree)

12. I want immediate feedback available for all my sessions with my clients (Strongly Agree, Agree, Somewhat Agree, Disagree, Somewhat Disagree, Strongly Disagree)

13. Open-ended-- What did you like best about the immediate feedback?

14. Open-ended-- Was the content of the feedback provided important to you? Please explain.

15. Open-ended- How frequent was feedback provided via written feedback?

16. Open-ended - Any additional information or suggestions? 